\title{
Evidence for the significant role of sea surface temperature distributions over remote tropical oceans in tropical cyclone intensity
}

\author{
Anitha Kumari Hegde ${ }^{1} \cdot$ Ryuichi Kawamura $^{1} \cdot$ Tetsuya Kawano $^{1}$
}

Received: 17 June 2015 / Accepted: 24 September 2015 / Published online: 26 October 2015

(C) The Author(s) 2015. This article is published with open access at Springerlink.com

\begin{abstract}
The role of remote ocean sea surface temperature (SST) in regulating tropical cyclone (TC) characteristics has been examined by performing numerical experiments with a regional scale model. Model simulations have been carried out to simulate typhoon Man-yi (July 2007), in our case study, under a range of SST conditions over the Indian Ocean and the South China Sea. The intensity and track of the cyclone have been systematically changed in sensitivity simulations of cool and warm SSTs over that region, following its peak phase. Warm oceans can substantially reduce the intensification of western North Pacific cyclones, whereas cool oceans can enhance their strength. This is intimately associated with the enhancement/weakening of the moisture supply through the moisture conveyor belt (MCB) in the lower troposphere, from the Indian Ocean and South China Sea into the vicinity of the cyclone center. When the MCB is interrupted over the South China Sea in warm SST occurrences, the large-scale transport of moisture into the cyclone system is significantly reduced, leading to the weakening of the cyclone intensity and to the eastward shift of its track. This study shows that changes in remote tropical ocean SST can also modulate TCs and thus can help in improving the forecasting of TC intensities and tracks.
\end{abstract}

Keywords Sea surface temperature - Typhoon intensity · Moisture transport $\cdot$ WRF model

Anitha Kumari Hegde

hegdeanitha@gmail.com

1 Department of Earth and Planetary Sciences, Faculty of Sciences, Kyushu University, Fukuoka 812-8581, Japan

\section{Introduction}

The western North Pacific basin is the most active region for tropical cyclones (TCs) in the world (Hope 1979; Ritchie and Holland 1999). Approximately $30 \%$ of TCs originate in this region and cause massive human and economic losses over Japan, South Korea, Taiwan, China, the Philippines, Indonesia, and Malaysia each year as a result of heavy rainfall and severe flooding. Significant uncertainties remain in the forecast of TCs intensity and track. The prediction of TCs helps local decision makers to take adequate emergency measures, such as the evacuation of coastal residents, in order to protect populations and minimize casualties. Although there have been lots of studies on TC track prediction (e.g., Krishnamurti and Oosterhof 1989; Mathur 1991; Aberson 1998; Goerss 2007; Hsiao et al. 2009; Huang et al. 2011; Kim et al. 2012) over the last 30 years, no appreciable improvements in TC intensity prediction have been made (Rappaport et al. 2009; RiosBerrios et al. 2014). Accordingly, in recent years, the accurate prediction of TC intensity has become an important impediment to scientific progress.

Large errors in TC intensity prediction possibly stem from the uncertainty in the quantification of the moisture supply from a warm ocean into the TC system. Braun (2006) and Yang et al. (2011) examined water budgets of TCs and pointed out that the oceanic source of water vapor within the inner core represents a very small portion of the horizontal import of vapor, and that the net horizontal convergence of vapor into the storm constitutes a large part of net condensation. It is still uncertain, however, whether the secondary TC circulation alone does contribute to the horizontal import of vapor at low levels into the vicinity of the TC center. Another view suggests the large-scale import of 
Table 1 Details of model configurations (simulations with and without nesting)

\begin{tabular}{lll}
\hline Details & Without nesting & With nesting (for high-resolution moving nest) \\
\hline Horizontal resolution & $20 \mathrm{~km}$ & $6.67 \mathrm{~km}$ \\
No. of grids & $605 \times 254$ & $160 \times 163$ \\
Vertical levels & 35 & 35 \\
Domain coverage & Over the Asian summer monsoon region & Over the western North Pacific Ocean region \\
Convection & Kain-Fritsch scheme (Kain and Fritsch 1993; Li 2013) & Kain-Fritsch scheme (Kain and Fritsch 1993; Li 2013) \\
Surface processes & Noah scheme (Chen et al. 2001) & Noah scheme (Chen et al. 2001) \\
Radiation & Dudhia scheme for shortwave radiation. RRTM scheme & Dudhia scheme for shortwave radiation. RRTM scheme \\
& (Mlawer et al. 1997) for longwave radiation & (Mlawer et al. 1997) for longwave radiation \\
Planetary boundary layer & Yonsei University scheme & Yonsei University scheme \\
Cloud microphysics & WRF double moment (WSM6) scheme & WRF double moment (WSM6) scheme \\
Sea surface temperature & Real & Real \\
\hline
\end{tabular}

moisture from outside the TC system. Very recently, Kudo et al. (2014) pointed out that typhoons have the ability to accumulate large amounts of moisture from remote tropical oceans as a result of the interaction of their Rossby wave response with the background flow. In the case of a typical typhoon (Man-yi, July 2007) that approached Japan, it was found that the total precipitable water around the typhoon center is maintained by the moisture supply from remote oceans rather than from the underlying ocean. They (Kudo et al. 2014) named this type of large-scale moisture transport from the tropics into the vicinity of the typhoon center the "moisture conveyor belt (MCB)." This MCB might, in turn, facilitate development and maintenance of the typhoon itself. If this working hypothesis is correct, the distribution of sea surface temperature (SST) over remote tropical oceans, combined with the distribution of SST in underlying waters, will play a significant role in regulating typhoon intensity.

To clarify this issue, we performed SST sensitivity experiments in the context of typhoon Man-yi (2007) using an Advanced Research Weather Research and Forecasting (WRF-ARW) model with a nesting technique. The present study specifically focuses on the possible remote effect of Indian Ocean and South China Sea SST anomalies on the intensity and track of the typhoon that approached Japan.

\section{Experimental design}

Typhoon Man-yi formed as a tropical depression in the western North Pacific Ocean on July 8, 2007. The storm gradually built in power to typhoon status on July 10 and approached western Japan via Okinawa Island, which remotely reinforced the Baiu/Meiyu frontal zone and caused heavy rainfall over Japan (Hirata and Kawamura 2014). According to the Japan Meteorological Agency, the lowest minimum sea level pressure (SLP) recorded during this event was $930 \mathrm{hPa}$. We focus on the period from 0000 UTC on July 9 to 1800 UTC on July 14, 2007 covering the early, developing, mature, and decaying stages of the typhoon.

The simulations are performed using the WRF-ARW model, version 3.5, which was developed by the National Center for Atmospheric Research (NCAR) (Skamarock and Weisman 2009). The model serves a wide range of meteorological applications across scales ranging from meters to thousands of kilometers in both atmospheric research and operational forecasting. It uses the Euler equations for non-hydrostatic compressible flow, terrain-following hydrostatic pressure, and an Arakawa-C type horizontal grid (Skamarock et al. 2008). The simulation experiments use the National Centers for Environmental PredictionsFinal (NCEP-FNL) reanalysis data set. The NCEP 6-hour FNL data available at $1^{\circ} \times 1^{\circ}$ resolution are used for initial and boundary conditions. The model initiation time was July 9, 0000 UTC. The model domain is the Asian summer monsoon region and the Northwestern Pacific sector $\left(10^{\circ} \mathrm{S}\right.$ to $35^{\circ} \mathrm{N}$ and $64^{\circ} \mathrm{E}$ to $175^{\circ} \mathrm{E}$ ), and the details of model configurations are given in Table 1 . The best-track data observations (OBS) are from the Japan Meteorological Agency, Regional Specialized Meteorological Center of TokyoTyphoon Center.

In the present study, the SST over the Indian Ocean $\left(10^{\circ} \mathrm{S}-26^{\circ} \mathrm{N}\right.$ and $\left.64^{\circ} \mathrm{E}-105^{\circ} \mathrm{E}\right)$ has been modified by adding (warming) and subtracting (cooling) 1,2 , and $3{ }^{\circ} \mathrm{C}$ to the original SST. The names of the experiments are CNTL (control run), CS1, CS2, CS3, WS1, WS2, and WS3. The Indian Ocean SST is decreased by $1{ }^{\circ} \mathrm{C}$ in the CS1 sensitivity simulation, by $2{ }^{\circ} \mathrm{C}$ in $\mathrm{CS} 2$, and by $3{ }^{\circ} \mathrm{C}$ in $\mathrm{CS} 3$. In warm SST experiments, the Indian Ocean SST is increased by 1,2 , and $3{ }^{\circ} \mathrm{C}$ for $\mathrm{WS} 1, \mathrm{WS} 2$, and $\mathrm{WS} 3$, respectively (Fig. 3).

The linear equation $\operatorname{SST}_{\text {mod }}(x)=S S T_{\text {org }}(x)+\mathrm{f}(x)$ is applied to modify the SST of the Indian Ocean 

central pressure for simulated CNTL experiments using techniques with and without nesting in comparison with OBS. Each integration time in the $\mathrm{x}$-axis contains 6-hourly data from UTC on July 14 . The vertical green lines refer the classifications of early, developing, mature, and decay phases of the typhoon based on OBS
Fig. 1 Time evolution of the 0000 UTC on July 9 to 1800

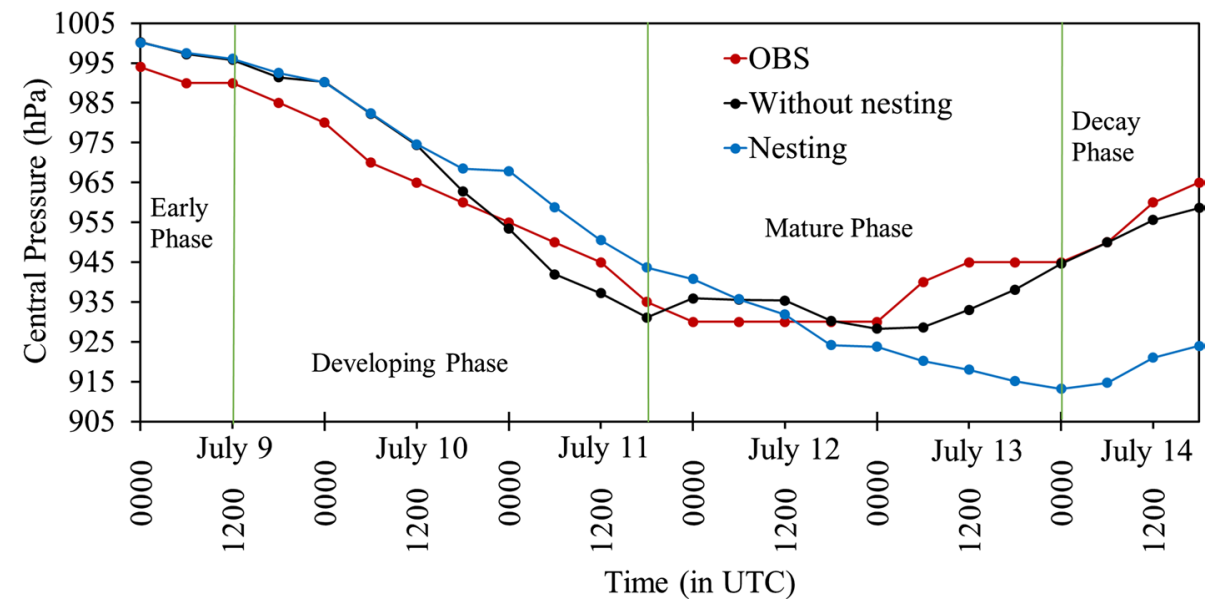

from $10^{\circ} \mathrm{S}$ to $26^{\circ} \mathrm{N}$ and from $64^{\circ} \mathrm{E}$ to $105^{\circ} \mathrm{E}$ throughout the simulation. $S S T_{\bmod }(x)$ refers to modified SST, $\operatorname{SST}_{\text {org }}(x)$ to the original SST, and $x$ is the longitude. $\mathrm{f}(x)=-\frac{\Delta T}{2}\left[\tanh \left(\frac{x-112.5}{\lambda}\right)-1\right]$ is a hyper tangent function applied over $10^{\circ} \mathrm{S}-26^{\circ} \mathrm{N}$ and $105^{\circ} \mathrm{E}-120^{\circ} \mathrm{E}$ in order to avoid the undesirable effect of large SST discontinuities. $\Delta T$ is the SST sensitivity for cool/warm experiments, 112.5 is the mean longitude $\left(\frac{105+120}{2}\right)$, and $\lambda$ equals 5 , a constant scale width (longitude) of the hyper tangent function. The South China Sea SST is also modified according to the above hyper tangent equation, and is shown in Fig. 3.

\section{Results from experiments without nesting}

Although our main aim is not to produce a comparative study, we have examined trends for intensity and track obtained from the CNTL experiment with respect to OBS. The simulated intensities obtained from experiments with and without nesting followed similar trends. Excepting the further intensification of the typhoon in the simulation with nesting after 0000 UTC on July 13, simulations and observations (OBS) compare well (Fig. 1). The simulated track experiments with and without nesting followed a similar trend, with a displacement difference of around $50 \mathrm{~km}$ during the integration as compared to OBS (Fig. 2).

\subsection{Changes in background circulation states}

Figure 3 shows the spatial patterns of SST, SLP, and vertically integrated moisture flux (VIMF) time-averaged over the early and developing stages of the typhoon from 0000 UTC on July 9 to 1800 UTC on July 11, 2007. Note that VIMF is integrated from $950 \mathrm{hPa}$ to $100 \mathrm{hPa}$. It is evident that SLP and VIMF fields over the Indian Ocean and South China Sea are significantly changed in response to SST

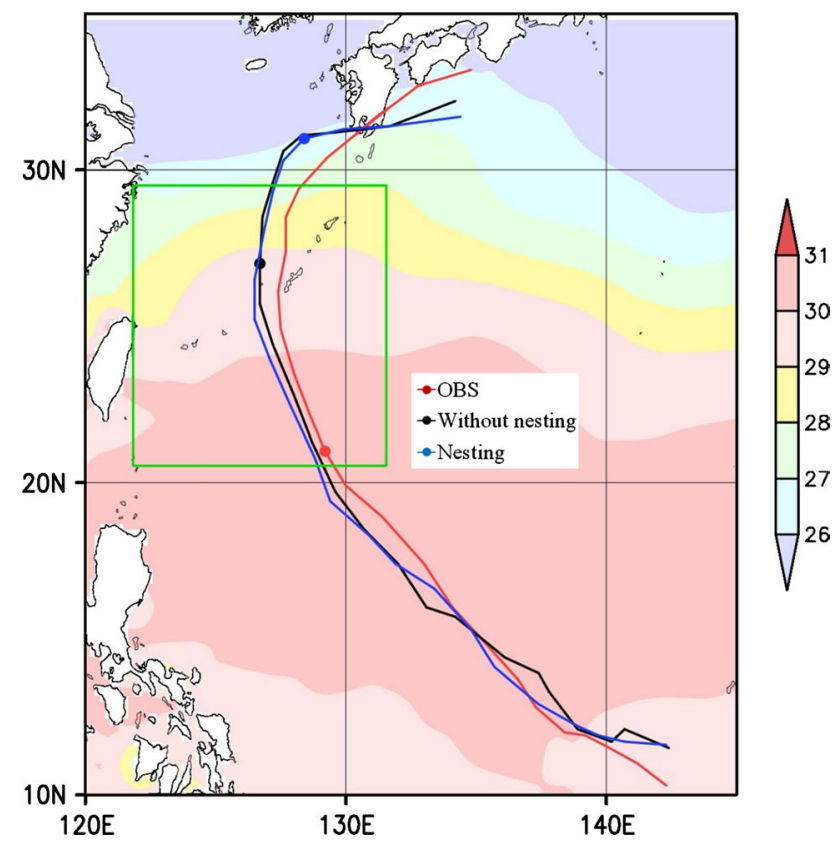

Fig. 2 Simulated typhoon tracks with and without nesting compared with OBS (from 0000 UTC on July 9 to 1800 UTC on July 14, 2007). The intensity peaks are shown in closed circles with respective colors. The background shading denotes the average SST distribution (from CNTL run, in ${ }^{\circ} \mathrm{C}$ ) over Southern Japan. The green rectangle represents the domain size of the moving nest at 1800 UTC on July 12

changes. The warm SST anomalies over the Indian Ocean and the South China Sea favor the reinforcement of the monsoon trough over the Indian subcontinent and the Bay of Bengal. In contrast, in the cooling experiments, SLP is high over the Bay of Bengal and the South China Sea. On the other hand, SLP distributions over the western North Pacific Ocean are almost unchanged in all six SST experiments. A remarkably low SLP area in the Eastern Philippines at each run corresponds to the simulated typhoon. 
Fig. 3 Spatial patterns of SST, SLP, and vertically integrated moisture flux (VIMF) timeaveraged over the early and developing phases (0000 UTC on July 9 to 1800 UTC on July 11) of typhoon Man-Yi for warm SST (WS3, WS2, and WS1) and cool SST (CS1, CS2, and CS3) experiments. The shaded interval for SST is $1{ }^{\circ} \mathrm{C}$. The contoured interval for SLP is $2 \mathrm{hPa}$. The vectors (green) denote VIMF in $\mathrm{kg} \mathrm{m}^{-1} \mathrm{~s}^{-1}$.

The reference arrow is $6000 \mathrm{~kg} \mathrm{~m}^{-1} \mathrm{~s}^{-1}$. Fluxes of less than $2500 \mathrm{~kg} \mathrm{~m}^{-1} \mathrm{~s}^{-1}$ have been suppressed
Fig. 4 Time evolution of the difference in central pressure of the simulated cool SST (CS1, CS2, and CS3) and warm SST (WS1, WS2, and WS3) experiments with respect to CNTL. Each line is plotted by 6-hourly pressure values from 0000 UTC on July 9 to 1800 UTC on 14 July. The vertical green lines are classifications of early, developing, mature, and decay phases of the typhoon based on OBS
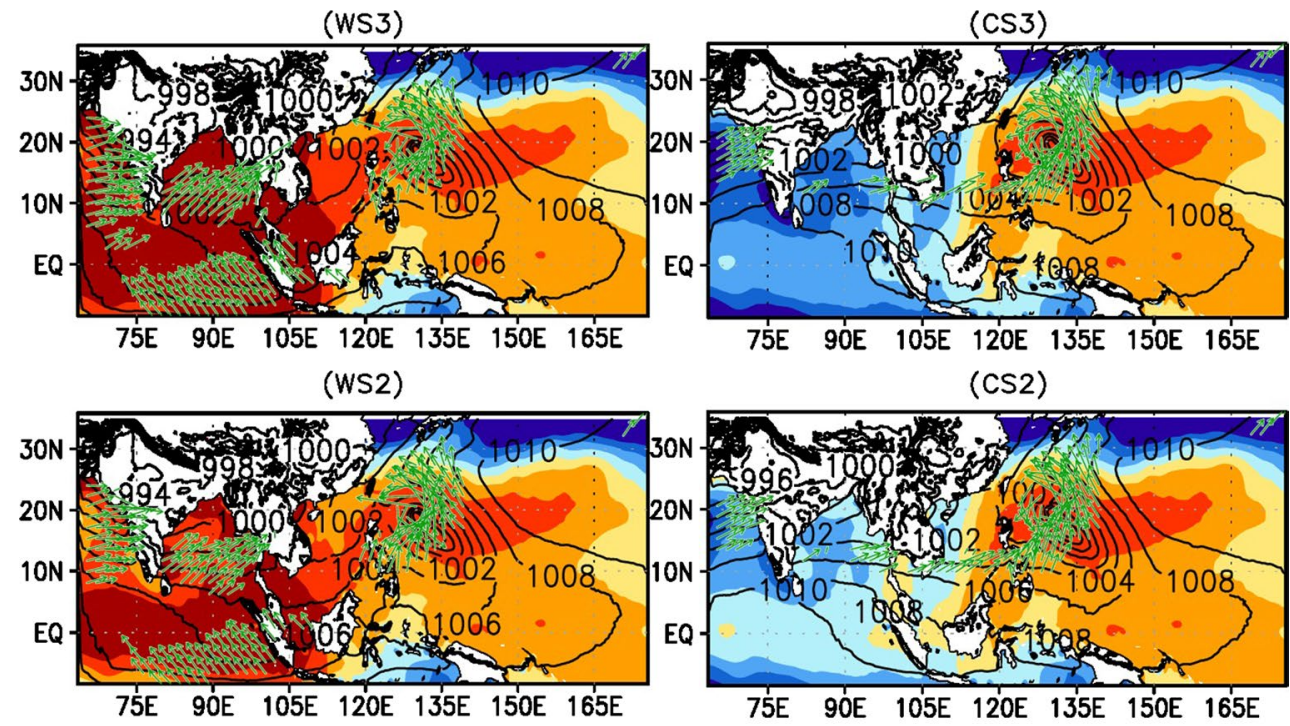

(WS1)
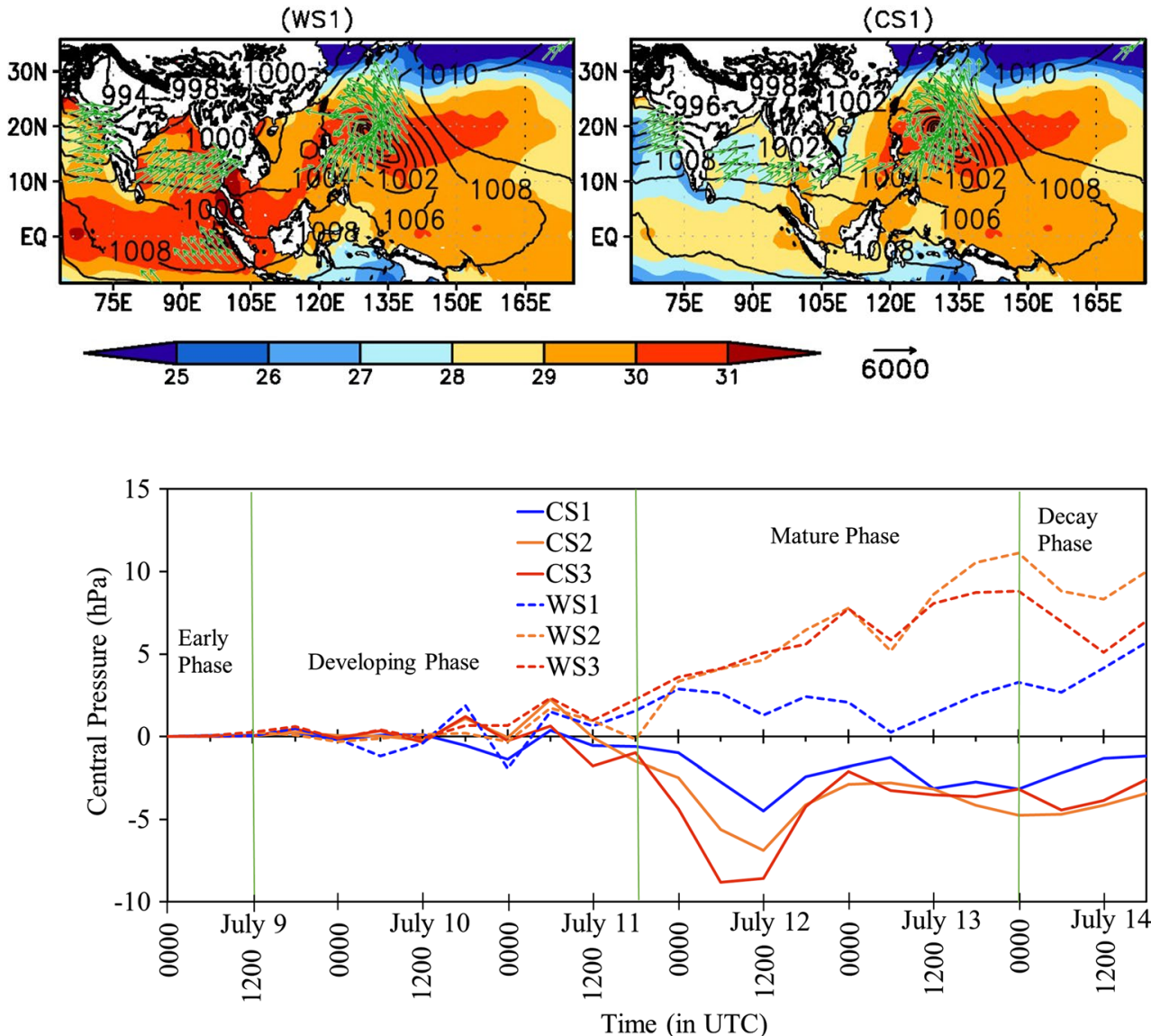

This low SLP area is also quite similar in the different experiments, suggesting that a significant influence by the Indian Ocean and South China Sea SST changes can be hardly seen in the behavior of the typhoon during its early phase. What we would like to emphasize here is that remote SST plays only a little role in the formation and in the early stage of this tropical cyclone.

\subsection{Intensity and track of the simulated typhoon}

Figure 4 shows time evolutions of the difference in the central pressure of typhoon Man-yi in cool and warm SST experiments with respect to the CNTL run. Some differences in intensity may arise between CNTL and the six SST runs during the developing phase of the typhoon, but 


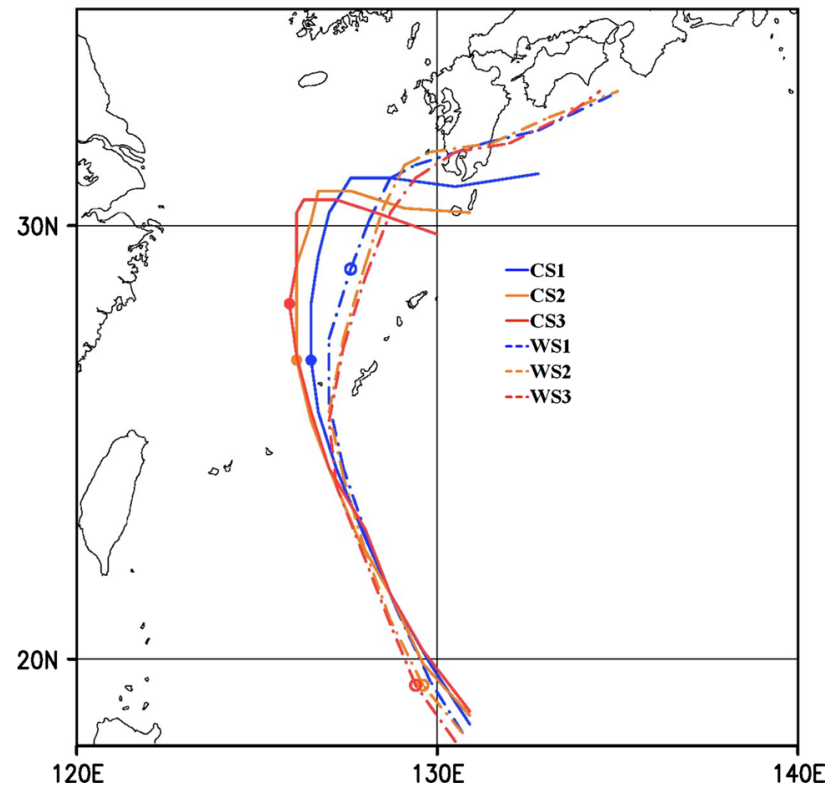

Fig. 5 Simulated typhoon tracks for the cool SST (CS1, CS2, and CS3) and warm SST (WS1, WS2, and WS3) experiments during the mature and decay phases (from 1800 UTC on July 11 to 1800 UTC on July 14, 2007). The peak intensities of typhoons simulated by cool and warm SST runs are depicted in closed and open circles with respective colors

there are few systematic differences between the six SST experiments during that period, which confirms that Indian Ocean and South China Sea SST changes do not significantly affect the intensity of the typhoon at its early stage. However, this is not the case following the mature phase (July 11, 1800 UTC) of the typhoon. Its intensity tends to become weak/strong during the mature stage in warm/ cool SST experiments compared with the CNTL run. The CS3 run has reduced the central pressure by approximately $8 \mathrm{hPa}$ compared to the CNTL run, whereas the warm WS3 and WS2 runs failed to simulate the sharp drop in central pressure as the typhoon enters its mature stage. The reduction (enhancement) in central pressure obtained in sensitivity experiments compared to the CNTL run clearly indicates that the intensity of the cyclone increases (decreases) when cool (warm) SST conditions prevail over the Indian Ocean and South China Sea. On July 14, the typhoon decays and then transforms into an extratropical cyclone. During the decay phase (starting on July 14, 0000 UTC), the cool SST runs are different from the CNTL but not so much as the warm SST runs.

The simulated typhoon tracks for CS1, CS2, CS3, WS1, WS2, and WS3 are shown in Fig. 5 from July 11 2007, 1800 UTC to July 14, 1800 UTC (following the mature stage of the typhoon). It suggests that the warm SST runs (open circles in WS2 and WS3) produce an early intensification of typhoon system compared to the cool SST runs (closed circles). The simulated tracks of the typhoon are shifted westward for the cool SST runs, whereas in the warm SST runs its tracks shift toward Kyushu Island (approximately $31^{\circ} \mathrm{N}$ to $34^{\circ} \mathrm{N}$ and $129.5^{\circ} \mathrm{E}$ to $132^{\circ} \mathrm{E}$ ). During the decaying phase (weak intensity), simulated tracks of all the typhoons are positioned toward the southeastern side of Kyushu Island, Japan.

As already indicated in Fig. 3, changes in background circulation due to changes in SST are limited to the Indian Ocean and South China Sea regions during the early developing stage of the typhoon. However, it should be noted that during the mature phase, the intensities and tracks of typhoons are systematically influenced by Indian Ocean and South China Sea SST changes. This will be discussed further.

\subsection{Moisture transportation through the MCB}

Figure 6 illustrates the spatial patterns and magnitudes of SLP and VIMF for CNTL at 0000 and 1200 UTC on July 10,11 and 12. It is noteworthy that the MCB is a narrow band of high VIMF (Kudo et al. 2014). The moisture supply through the MCB is not yet organized at 0000 or 1200 UTC on July 10 (early stage of the typhoon), but after 0000 UTC on July 11 there is a continuous supply of moisture transported from the Indian Ocean and the South China Sea toward the typhoon. About 1 day after the establishment of the MCB, significant differences in typhoon intensity become evident between the six SST experiments, as shown in Fig. 4.

Figure 7 is analogous to Fig. 6 but showing the results for warm and cool SST-sensitive experiments at 1200 UTC on July 12, to clarify the difference in MCB between them. In cool SST experiments (CS1, CS2, and CS3), the MCB is well organized from the Indian Ocean and South China Sea to the vicinity of the typhoon center, which fuels the typhoon over the western North Pacific Ocean. This means that the MCB plays a vital role in transporting a large amount of moisture from remote tropical oceans. In contrast, the warm SST experiments yield a weakening of the MCB over the South China Sea region. Particularly in WS2 and WS3, the MCB is clearly interrupted over that region and separated into two branches over the Indian Ocean and western North Pacific Ocean. This separation leads to the significant reduction in large-scale moisture transport from the Indian Ocean and South China Sea regions into the vicinity of the typhoon center. On the other hand, the warm SST anomalies over the Indian Ocean favor the deepening of the monsoon trough along with strong convection (e.g., Wang et al. 2001; Wu and Wang 2001). The ocean is the major supplier of moisture for the Indian monsoon region and warm ocean conditions can also lead to an early onset and an intensification of summer monsoons (e.g., 
Fig. 6 Spatial patterns of SLP (contours), VIMF (green vectors), and its magnitude (shaded) for the CNTL experiment at 0000 and 1200 UTC on July 10, 0000 and 1200 UTC on July 11, 0000 and 1200 UTC on July 12 . The contoured interval is $5 \mathrm{hPa}$. The reference arrow is $6000 \mathrm{~kg} \mathrm{~m}^{-1} \mathrm{~s}^{-1}$. Fluxes of less than $700 \mathrm{~kg} \mathrm{~m}^{-1} \mathrm{~s}^{-1}$ have been suppressed
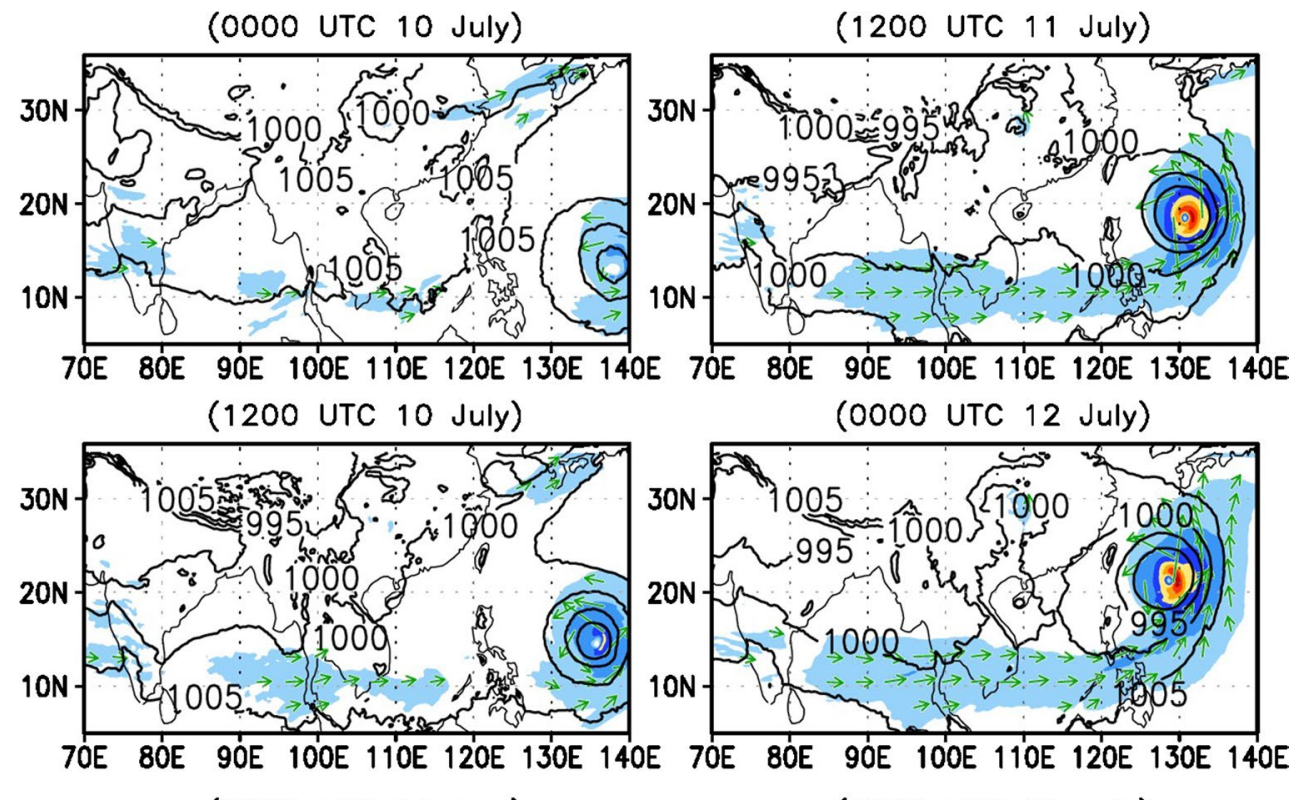

(0000 UTC 11 July)
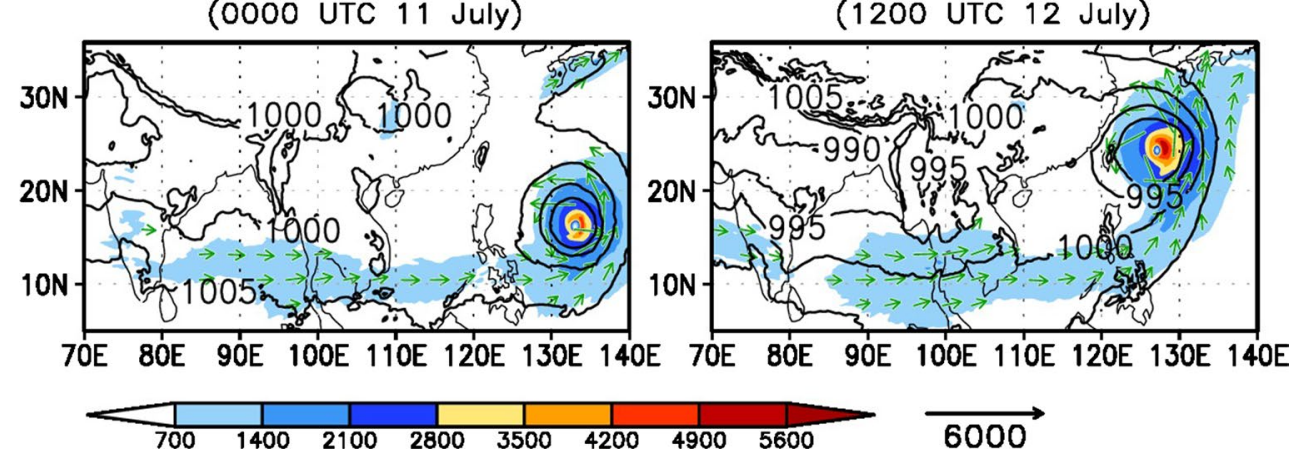

6000
Sijikumar and Rajeev 2012; Zhou and Murtugudde 2014). It appears that the significant change in monsoon circulation over the Indian Ocean caused by the warm SST anomalies gives rise to the separation of the MCB.

The simulated spatial distributions of surface latent heat flux and $925 \mathrm{hPa}$ wind vector over the South China Sea and Philippine Sea at 1200 UTC on July 12 for warm and cool SST experiments are represented in Fig. 8. Compared with the warm SST experiments, areas of enhanced latent heat flux with strong near-surface winds expand from the vicinity of the typhoon center into the South China Sea region in CS1, CS2, and CS3, which suggests that moisture from remote waters intrudes into the typhoon center through the MCB. In contrast, attenuated winds can be seen along the MCB in WS1, WS2, and WS3, resulting in decreased moisture supply from the ocean. Both lower moisture supply from the ocean and an ill-organized MCB (Fig. 7) contribute to less moisture being transported into the typhoon system from remote tropical oceans. Consequently, it appears that such significant changes suppress the development of the typhoon itself. In fact, the typhoon intensity at WS1, WS2, and WS3 is obviously weak during the mature phase compared to that of CNTL, as shown in Fig. 4. Reverse situations are the case for CS1, CS2, and CS3. The welldefined MCB and associated enhanced moisture supply from the ocean are quite consistent with the deepening central pressure of the typhoon.

\section{Results from nesting experiments}

Although the $20 \mathrm{~km}$ resolution model simulations reasonably reproduce the observed TC intensity and track (Figs. 1, 2), many studies (e.g., Oouchi et al. 2006; Murakami et al. 2012; Srinivas et al. 2013; Strachan et al. 2013) showed the importance of using high-resolution models to capture the observed intensities and tracks of intense TCs. One might argue that the low-resolution simulation results presented in the previous section are less robust on the grounds that the basic structures around the typhoon center, such as the eye wall, are not well reproduced. To confirm that our findings depend little on the spatial resolution of the model used, we have simulated the typhoon Man-yi using a twoway interactive moving nest technique with two domains. 
Fig. 7 Same as Fig. 6 but for WS3 to CS3 sensitivity experiments at 1200 UTC on July 12 , 2007 during the mature phase of the typhoon
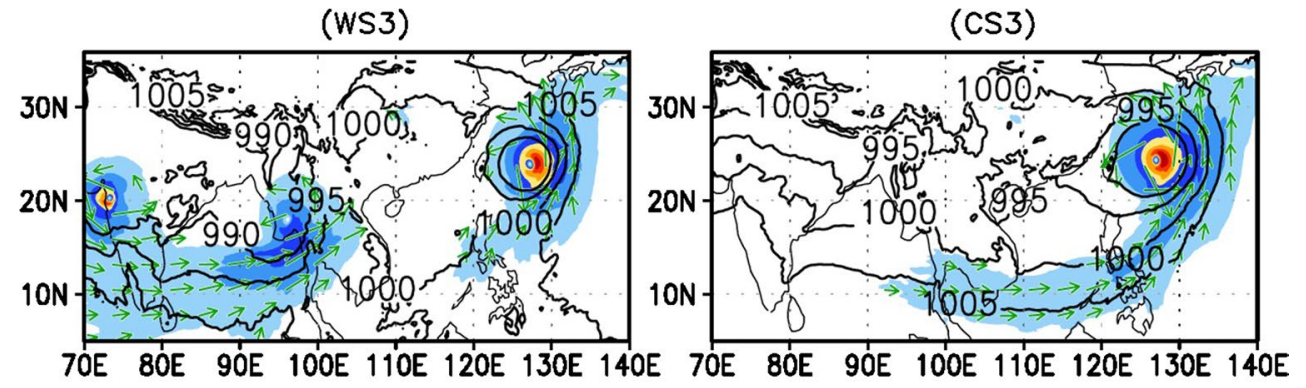

(WS2)
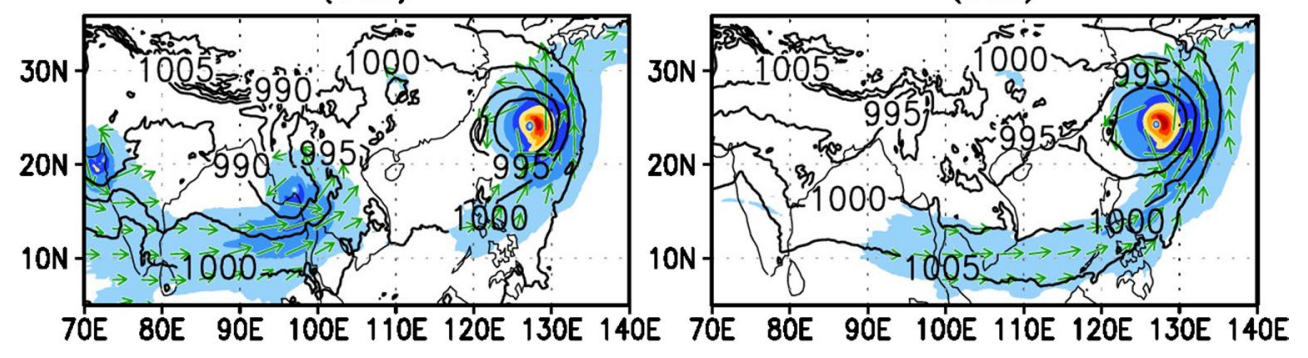

(WS1)
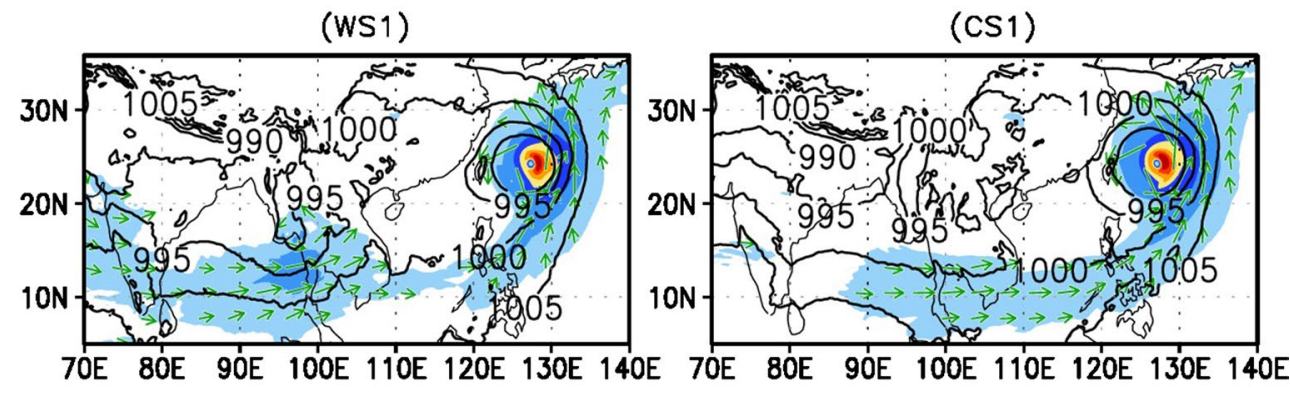

(CS1)

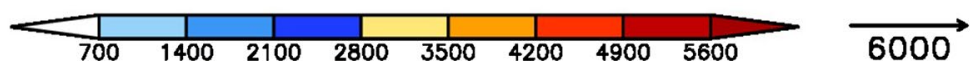

The technical information concerning compiling, running and the explanations of the moving nest are available at http://www2.mmm.ucar.edu/wrf/users/docs/user_guide_ V3/users_guide_chap5.htm. The mother domain $\left(10^{\circ} \mathrm{S}\right.$ to $35^{\circ} \mathrm{N}$ and $64^{\circ} \mathrm{E}$ to $175^{\circ} \mathrm{E}$ ) is of $20 \mathrm{~km}$ resolution, and the nested domain configuration details are given in Table 1. The domain of the moving nest is shown with a green color in Fig. 2 at 1800 UTC on July 12.

Figure 9 is analogous to Fig. 4, the difference being that it illustrates the results using the nesting technique. Here also (as in Fig. 4), we can see the difference in warm and cool SST experiments as compared to CNTL. The simulated typhoon intensities are stronger in the cool SST experiments (except CS2) than in the warm SST experiments (except WS1). At the decay phase (0000 UTC on July 14), there is little difference between the CNTL and cool SST runs, although the warm SST runs (except WS1) are still different from those of CNTL. Comparing with the results in Fig. 4, we obtained similar developments in the sense that systematic differences in the central pressure of the typhoon become evident between the SST runs after the typhoon reaches its mature stage. However, it appears that CS2 and WS1 do not show such a systematic tendency, which will be discussed later.

Figure 10 is analogous to Fig. 5 except for nesting sensitive experiments. The peaks of simulated intensities are much delayed in warm SST experiments (WS1, WS2, and WS3) and a little early in the case of CS1, CS2, and CS3. As in Fig. 5, here too the tracks associated with cool SSTs (CS3, CS2, and CS1) are shifted westward, and the ones associated with warm SSTs (WS3, WS2, and WS1) shift on the eastern side of Kyushu Island. The tracks of all the simulated typhoons are toward the southeastern side of Kyushu Island during the decay phase (weak intensity). These features are quite consistent with the low-resolution experiments conducted without applying the nesting technique.

Figure 11 is analogous to Fig. 7, except that the results are obtained applying the nesting technique at 1800 UTC on July 12. During this time step, the difference is much clearer compared than for other time steps. The perfect channeling of moisture through the MCB in CS1, CS2, and CS3 toward the typhoon center confirms the strong intensity during the mature phase. In contrast, we can see that the MCB is clearly interrupted over the South China Sea, 

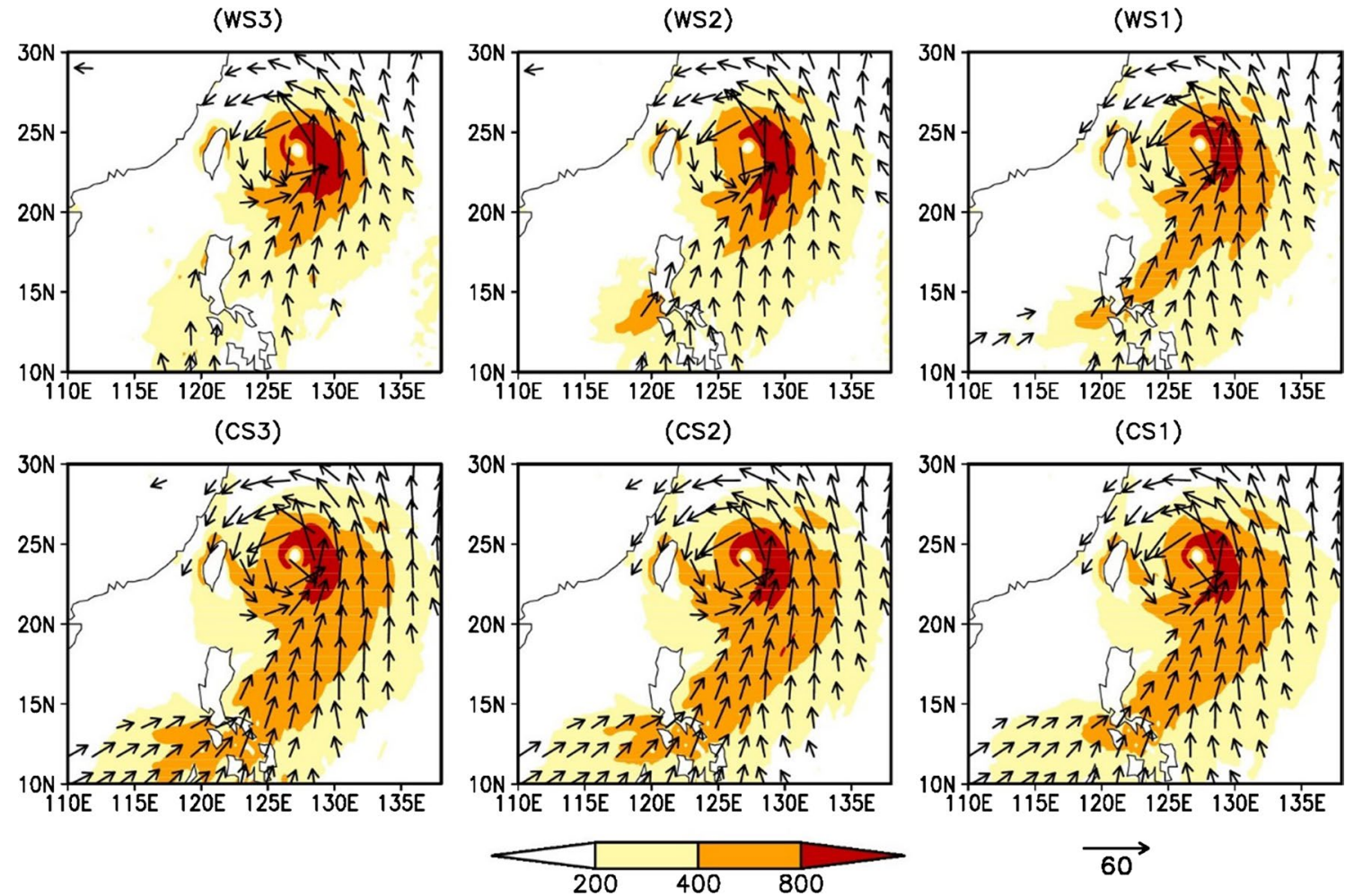

Fig. 8 Spatial patterns of surface turbulent latent heat flux (shaded) in $\mathrm{W} \mathrm{m}^{-2}$ and $925 \mathrm{hPa}$ horizontal wind vectors over the South China Sea and Philippine Sea at 1200 UTC on July 12 for the warm SST
(WS3, WS2, and WS1) and cool SST (CS1, CS2, and CS3) experiments. Wind speeds of less than $15 \mathrm{~m} \mathrm{~s}^{-1}$ have been suppressed. The reference arrow is $60 \mathrm{~m} \mathrm{~s}^{-1}$
Fig. 9 Same as Fig. 4 but from a high-resolution nested simulation

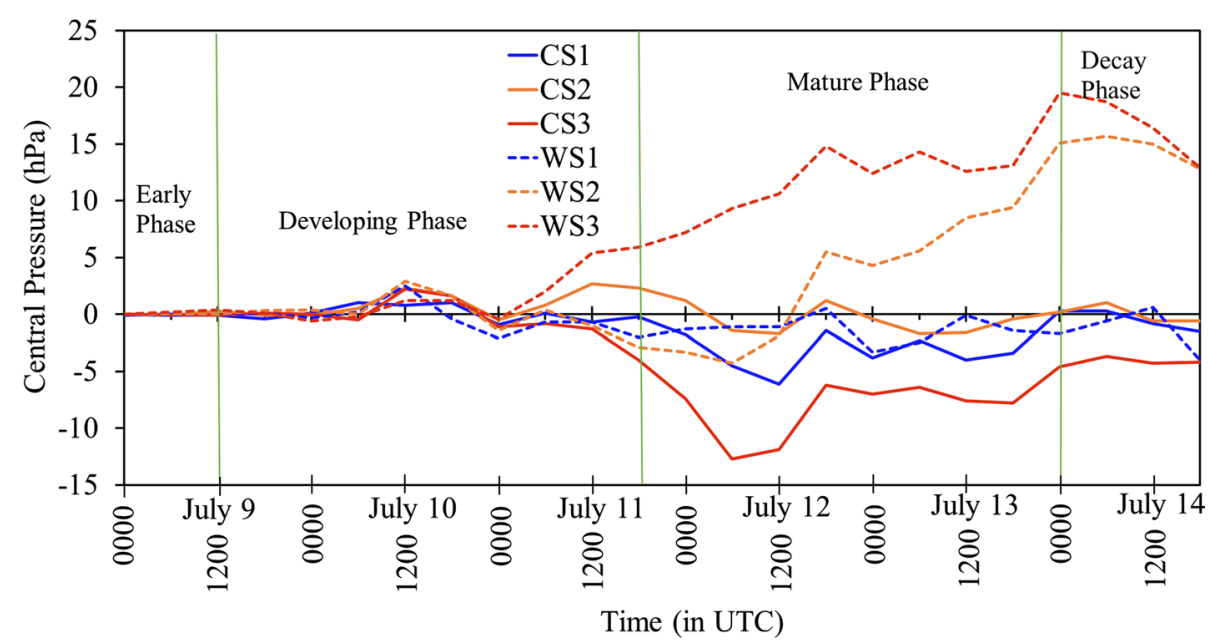

especially in WS2 and WS3. These characteristics are very similar to those of results presented in Fig. 7, suggesting that there are little differences between background circulation states resulting from experiments where the nesting technique is implemented or not. We also analyzed the spatial distributions of surface latent heat flux and $925-\mathrm{hPa}$ wind vector over the South China Sea and Philippine Sea for warm and cool SST runs derived from the two-way nesting and confirmed that the obtained patterns (not shown) quite resemble those of Fig. 8.

The magnitude of $850 \mathrm{hPa}$ wind and SLP in the vicinity of the typhoon center at 1800 UTC on July 12 is presented in Fig. 12. A common feature is that areas of extremely strong wind are located to the east of the typhoon center, and the eye is surrounded by strong winds. Such a ringshaped feature in the vicinity of the eye tends to be more 


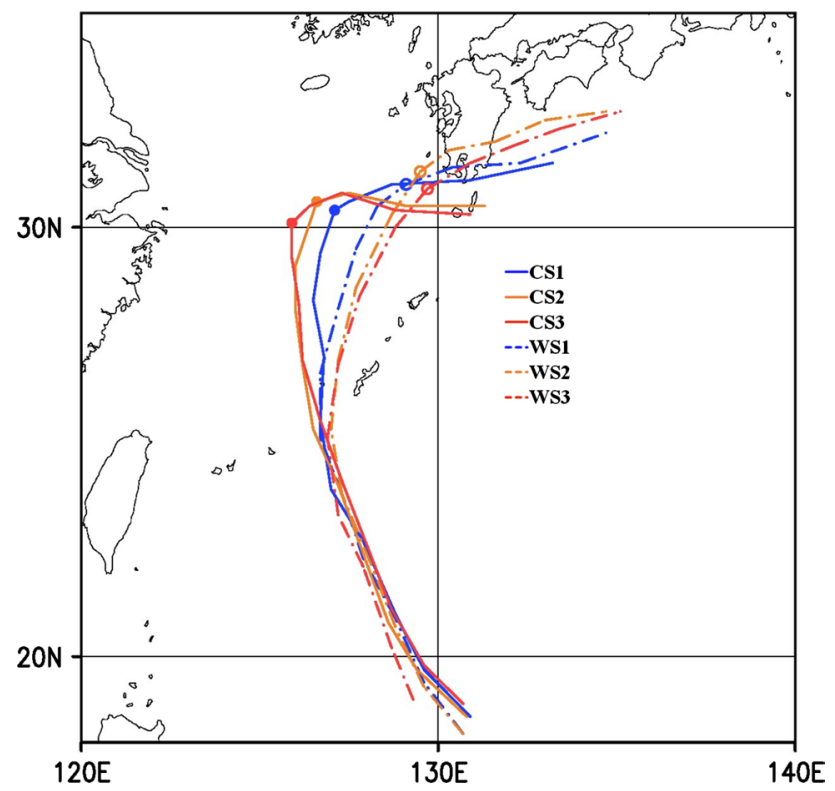

Fig. 10 Same as Fig. 5 but from a high-resolution nested simulation obvious in the cool SST experiments than in the warm ones. As already represented in Fig. 9, the central pressure of the typhoon in WS1 and CS2 differed from those simulated by the low-resolution model for which no nesting technique was applied. Comparing between WS1 and CS2 in Fig. 12 in terms of the typhoon eye structure, however, it seems that its structure in CS2 is more robust than that in WS1. This suggests that WS1 and CS2 in the highresolution simulation do not necessarily indicate different features from those of the low-resolution simulation.

More detailed structures of the typhoon system, the spatial patterns of the vertically integrated diabatic heating rate and horizontal divergence/convergence of moisture at 1800 UTC on July 12 for warm and cool SST experiments are presented in Fig. 13. It is evident that pronounced diabatic heating areas such as the eye wall and outer rainbands coincide well with those characterized by strong moisture flux convergence, suggesting that latent heat release constitutes a large part of the diabatic heating. The circular eye wall diabatic heating with condensation growth around the
Fig. 11 Same as Fig. 7 but at 1800 UTC on July 12 from a high-resolution nested simulation
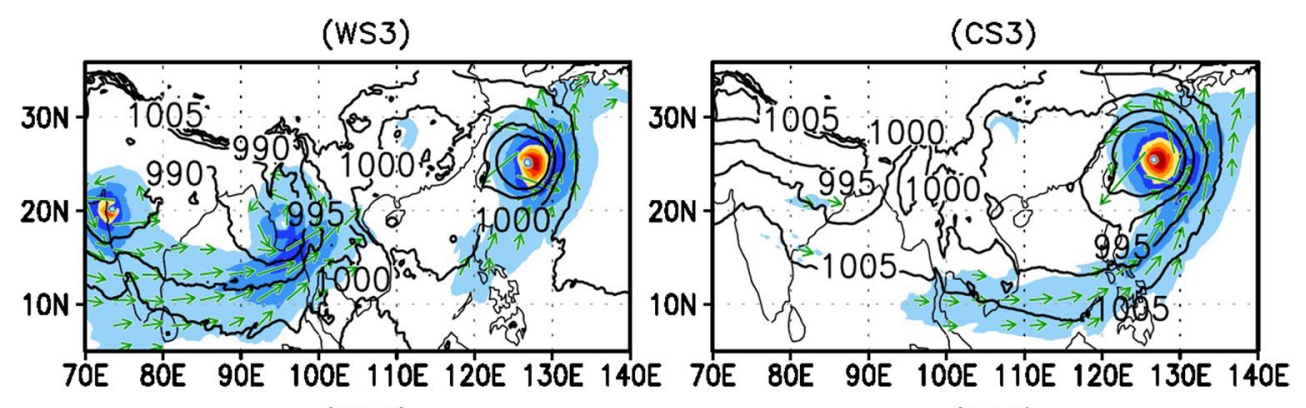

(WS2)
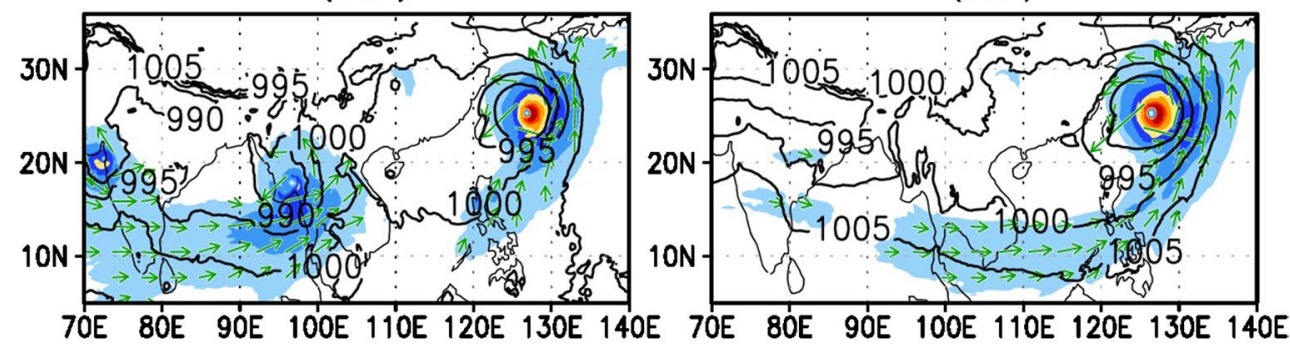

(WS1)
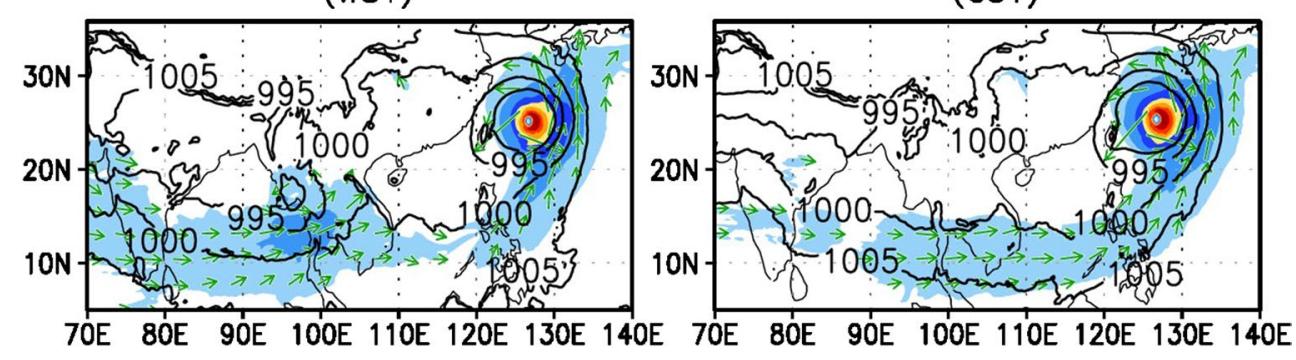

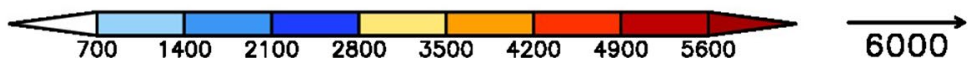


(WS3)

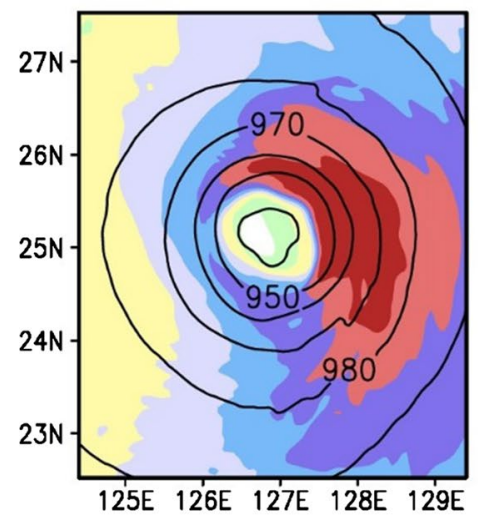

(CS3)

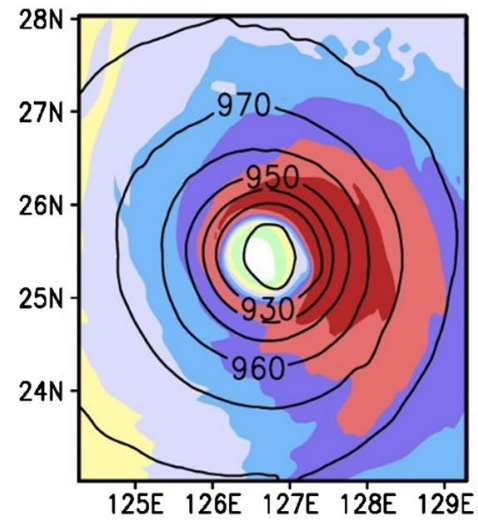

(WS2)

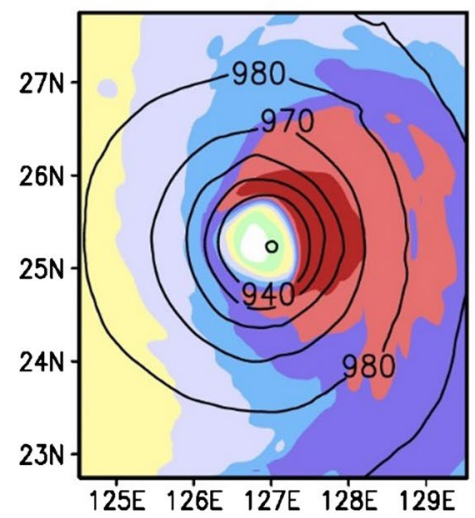

(cs2)

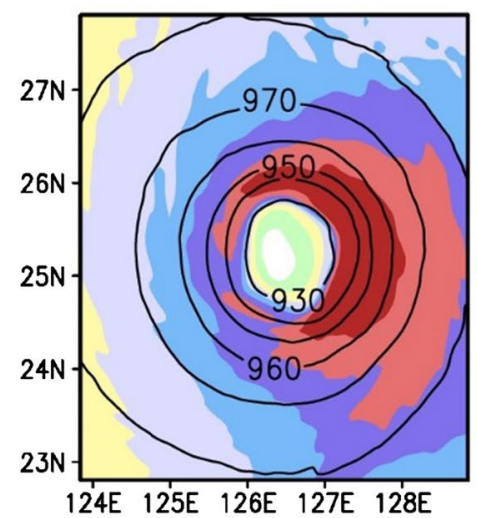

(WS1)

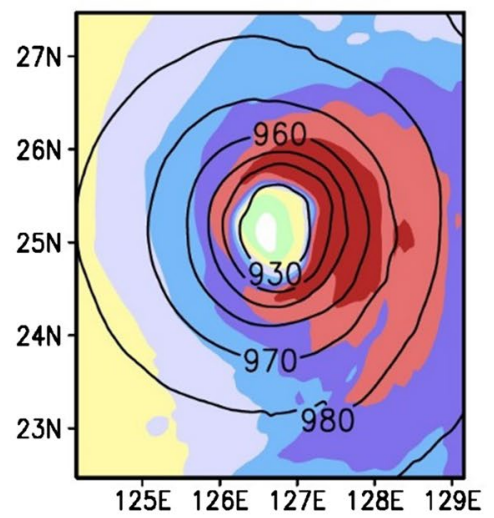

(CS1)

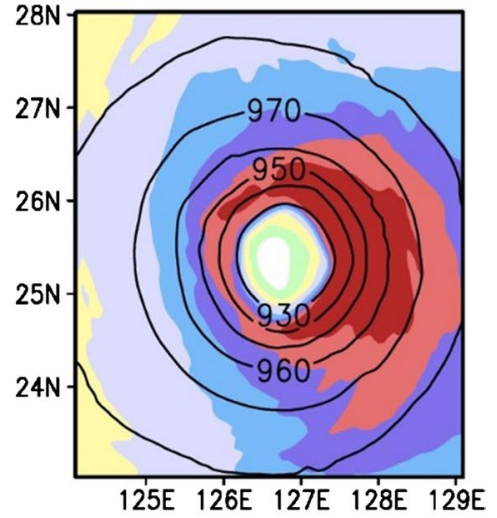

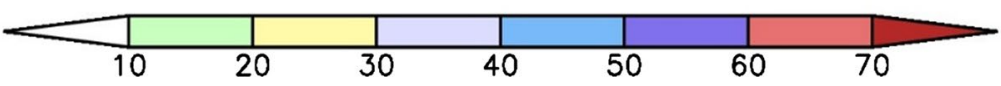

Fig. 12 Magnitude of $850 \mathrm{hPa}$ horizontal wind (shaded) and SLP (contours) at 1800 UTC on July 12 (during the mature phase) in the vicinity of the typhoon center. The shaded interval is $10 \mathrm{~m} \mathrm{~s}^{-1}$. The contoured interval for SLP is $10 \mathrm{hPa}$. The results are presented from a high-resolution nested simulation

South China Sea, following its peak phase, in association with the presence and absence of the MCB.

\section{Discussion}

This study shows that SST changes in the Indian Ocean and South China Sea significantly affected the intensity and track of typhoon Man-yi (July 2007) that approached Japan. Although SST changes in the Indian Ocean and South China Sea exert an influence on the intensification of the South Asian summer monsoon trough, its influence cannot extend into the background circulation field of the typhoon over the western North Pacific Ocean region. Despite this limitation, one may wonder why the intensity and track of the typhoon are systematically affected during its mature phase. Kudo et al. (2014) showed that a Rossby wave response to typhoon heating led to the intrusion of 
(WS3)

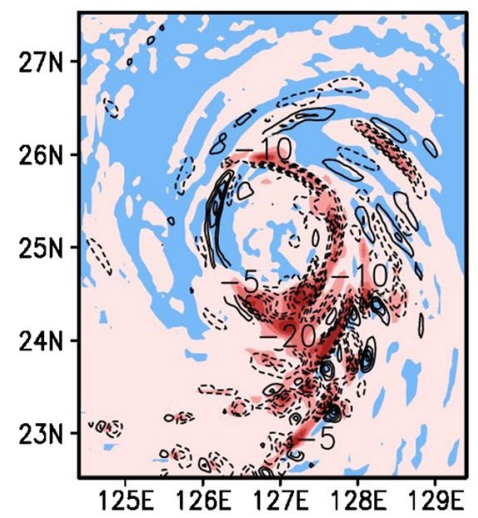

(CS3)

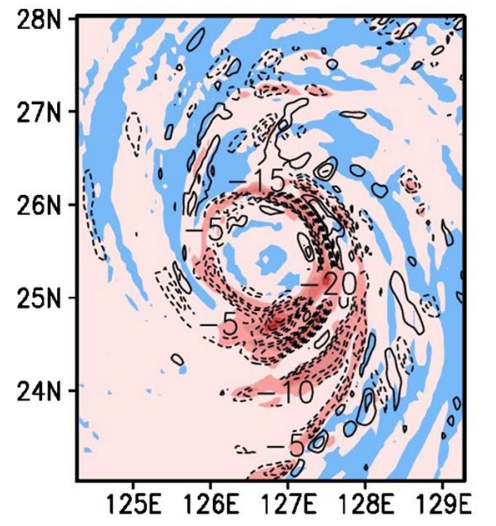

(WS2)

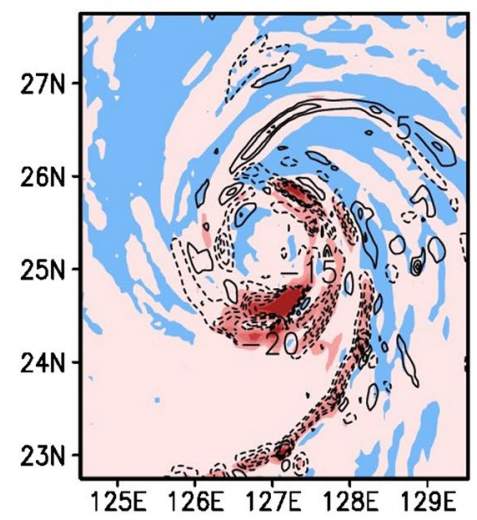

(CS2)

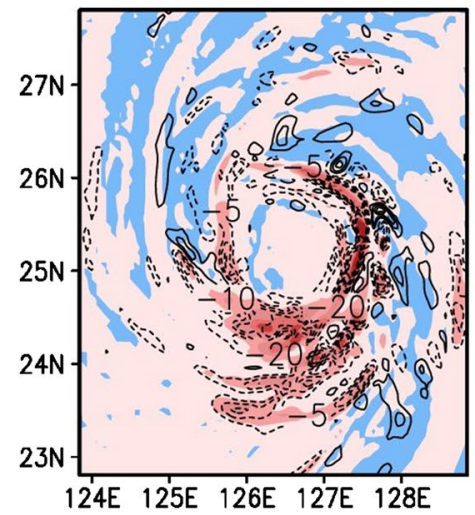

(WS1)

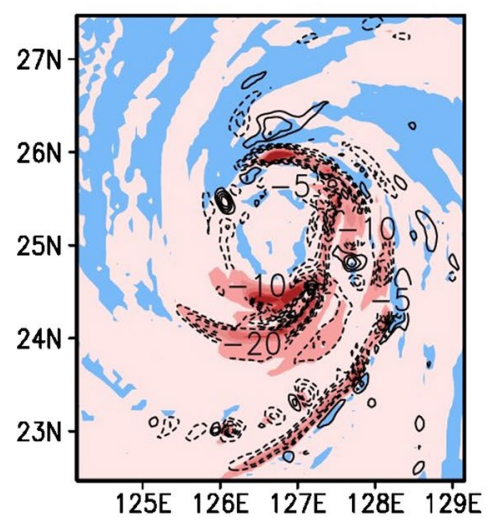

(CS1)

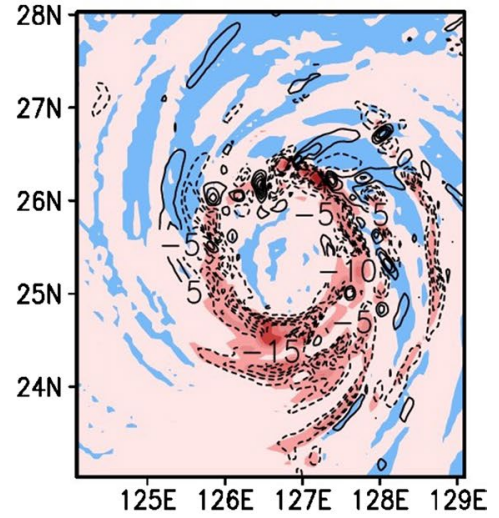

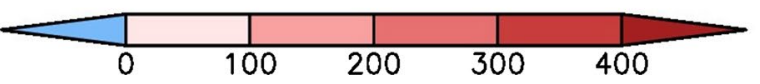

Fig. 13 Magnified view of vertically integrated diabatic heating rate (shaded) and horizontal convergence/divergence (contours) of moisture in the vicinity of the typhoon center at 1800 UTC on July 12 for warm and cool SST experiments. The diabatic heating rate (unit:
$\mathrm{K} \mathrm{h}^{-1}$ ) is integrated from $950 \mathrm{hPa}$ to $100 \mathrm{hPa}$. Dashed and solid contours denote negative (convergence) and positive (divergence) values, respectively (unit: $10^{-3} \mathrm{~kg} \mathrm{~m}^{-2} \mathrm{~s}^{-1}$ ). The results are presented from a high-resolution nested simulation lower tropospheric anomalous cyclonic circulation into the Bay of Bengal, eventually forming an MCB through the interaction with the background westerly flow. Even though the dispersive westward propagation of equatorial Rossby waves occurs, the MCB cannot be formed efficiently without the dominance of low-level monsoon westerlies over the South China Sea during boreal summer. The warm SST runs feature the deepening of the monsoon trough over the Indian subcontinent and the Bay of Bengal but an attenuated VIMF over the South China Sea region (Fig. 3). Large amounts of moisture are trapped in large-scale cyclonic circulation over the Indian subcontinent and the Bay of Bengal in warm SST simulations, which may lead to a strong monsoon over those regions. As a result, the MCB, which serves as a bridge between the Indian Ocean and the western North Pacific, is less structured in the warm SST experiments, whereas the reverse is true for the cool SST experiments (Figs. 7, 11). Once the MCB is established, large amounts of moisture can be transported into the vicinity of the typhoon center from the Indian Ocean and South China Sea regions, thereby contributing to intensification of the typhoon. Since the moisture supply from the ocean is enhanced along the MCB (Fig. 8), it can also facilitate moisture import into the typhoon system. According to Kudo et al. (2014), the substantial contribution of the moisture supply from remote tropical oceans to the total precipitable water around the center of typhoon Man-yi increased as it approached Japan.

Since the MCB is well structured as the typhoon develops (Fig. 6), the influence of large-scale moisture transport into the typhoon center through the MCB on its intensity is supposed to become significant at the later stage of the typhoon. In fact, the change in simulated typhoon intensity observed in different SST runs becomes evident as the typhoon approaches Japan. As the typhoon develops, a beta effect (beta drift) is expected to be predominant. Since a 
beta effect makes the typhoon migrate westward (Holland 1983), it is suggested that the beta effect is responsible for the westward/eastward shift of the typhoon track observed in cool/warm SST experiments, as shown in Figs. 5 and 10.

The case study of typhoon Man-yi shows the important role of Indian Ocean and South China Sea SSTs in defining typhoon intensity and track. Accordingly, in order to gain a proper understanding of typhoon development, we need to acknowledge that typhoons have the ability to accumulate large amounts of moisture from remote tropical oceans via the MCB. Our findings contribute to improvements in typhoon forecasting, particularly typhoon intensity and track over the western North Pacific Ocean during boreal summer. To increase the reliability of the results, we have begun conducting simulations with respect to other typhoons that have similar tracks, such as typhoon Halong (2002). To clarify the influence of the seasonal features of the background circulation field, we intend to conduct simulations of similar typhoons that occurred in the month of September or October, when the monsoon westerlies over South China Sea retreat.

Acknowledgments Comments by the editor and anonymous reviewers were extremely helpful. This research was supported by MEXT KAKENHI Grant Number 22106005 and JSPS KAKENHI Grant Number 15K13569. The best-track data used in this paper are available at the RSMC Tokyo-Typhoon Center (http://www.jma.go.jp/ jma/jma-eng/jma-center/rsmc-hp-pub-eg/RSMC_HP.htm).

Open Access This article is distributed under the terms of the Creative Commons Attribution 4.0 International License (http://creativecommons.org/licenses/by/4.0/), which permits unrestricted use, distribution, and reproduction in any medium, provided you give appropriate credit to the original author(s) and the source, provide a link to the Creative Commons license, and indicate if changes were made.

\section{References}

Aberson SD (1998) Five-day tropical cyclone track forecasts in the North Atlantic basin. Weather Forecast 13:1005-1015. doi:10.1175/1520-0434(1998)013<1005:FDTCTF>2.0.CO;2

Braun SA (2006) High-resolution simulation of Hurricane Bonnie (1998). Part II: water budget. J Atmos Sci 63:43-64. doi:10.1175/JAS3609.1

Chen F, Pielke S, Mitchell RK (2001) Development and application of land-surface models for mesoscale atmospheric models: Problems and promises. In: Lakshmi V, Albertson J, Schaake J (eds) Land surface hydrology, meteorology, and climate: observations and modeling. American Geophysical Union, Washington, DC, pp 107-135. doi:10.1029/WS003p0107

Goerss JS (2007) Prediction of consensus tropical cyclone track forecast error. Mon Weather Rev 135:1985-1993. doi:10.1175/ MWR3390.1

Hirata H, Kawamura R (2014) Scale interaction between typhoons and the North Pacific subtropical high and associated remote effects during the Baiu/Meiyu season. J Geophys Res Atmos 119:5157-5170. doi:10.1002/2013JD021430
Holland GJ (1983) Tropical cyclone motion: environmental interaction plus a beta effect. J Atmos Sci 40:328-342. doi:10.1175/1520-0469(1983)040<0328:TCMEIP>2.0.CO;2

Hope JR (1979) Tropical cyclone climatology, operational techniques for forecasting tropical cyclone intensity and movement. World Meteorol Organ I.2.1-I.2.10

Hsiao LF, Melinda SP, Chen DS, Huang KN, Yeh TC (2009) Sensitivity of typhoon track predictions in a regional prediction system to initial and lateral boundary conditions. J Appl Meteorol Climatol 48:1913-1928. doi:10.1175/2009JAMC2038.1

Huang HY, Wu CC, Wang Y (2011) The influence of island topography on typhoon track deflection. Mon Weather Rev 139:1708 1727. doi:10.1175/2011MWR3560.1

Kain JS, Fritsch JM (1993) Convective parameterization for mesoscale models: the Kain-Fritsch scheme. In: Emanuel KA, Raymond DJ (eds) The representation of cumulus convection in numerical models. American Meteorological Society, Boston, pp 1-246

Kim JH, Ho CH, Kim HS, Choi W (2012) 2010 Western North Pacific typhoon season: seasonal overview and forecast using a track-pattern-based model. Weather Forecast 27:730-743. doi:10.1175/WAF-D-11-00109.1

Krishnamurti TN, Oosterhof D (1989) Prediction of the life cycle of a super typhoon with a high-resolution global model. Bull Am Meteorol Soc 70:1218-1230. doi:10.1175/1520-0477(1989)070<1218:POTLCO >2.0.CO;2

Kudo T, Kawamura R, Hirata H, Ichiyanagi K, Tanoue M, Yoshimura K (2014) Large-scale vapor transport of remotely evaporated seawater by a Rossby wave response to typhoon forcing during the Baiu/Meiyu season as revealed by the JRA-55 reanalysis. J Geophys Res Atmos 119:8825-8838. doi:10.1002/201 4JD021999

Li X (2013) Sensitivity of WRF simulated typhoon track and intensity over the Northwest Pacific Ocean to cumulus schemes. Sci China Earth Sci 56:270-281. doi:10.1007/s11430-012-4486-0

Mathur MB (1991) The NMC's Quasi-Lagrangian model for hurricane prediction. Mon Weather Rev 119:1419-1447. doi:10.1175/1520-0493(1991)119<1419:TNMCQL>2.0.CO;2

Mlawer EJ, Taubman SJ, Brown PD, Iacono MJ, Clough SA (1997) Radiative transfer for inhomogeneous atmosphere: RRTM, a validated correlated-k model for the long wave. J Geophys Res 102:16663-16682. doi:10.1029/97JD00237

Murakami H, Wang Y, Yoshimura H, Mizuta R, Sugi M, Shindo E, Adachi Y, Yukimoto S, Hosaka M, Kusunoki S, Ose T, Kitoh A (2012) Future changes in tropical cyclone activity projected by the new high-resolution MRI-AGCM. J Clim 25:3237-3260. doi:10.1175/JCLI-D-11-00415.1

Oouchi K, Yoshimura J, Yoshimura H, Mizuta R, Kusunoki S, Noda A (2006) Tropical cyclone climatology in a global-warming climate as simulated in a $20 \mathrm{~km}$-mesh global atmospheric model: frequency and wind intensity analyses. J Meteorol Soc Jpn 84(2):259-276

Rappaport et al (2009) Advances and challenges at the National Hurricane Center. Weather Forecast 24:395-419. doi:10.1175/2008 WAF2222128.1

Rios-Berrios R, Vukicevic T, Tang B (2014) Adopting model uncertainties for tropical cyclone intensity prediction. Mon Weather Rev 142:72-78. doi:10.1175/MWR-D-13-00186.1

Ritchie EA, Holland GJ (1999) Large-scale patterns associated with tropical cyclogenesis in the Western Pacific. Mon Weather Rev 127:2027-2043. doi:10.1175/1520-0493(1999)127<2027:LSPA WT>2.0.CO;2

Sijikumar S, Rajeev K (2012) Role of the Arabian Sea warm pool on the precipitation characteristics during the monsoon onset period. J Clim 25:1890-1899. doi:10.1175/JCLI-D-11-00286.1

Skamarock WC, Weisman ML (2009) The impact of positive-definite moisture transport on NWP precipitation forecasts. Mon Weather Rev 137:488-494. doi:10.1175/2008MWR2583.1 
Skamarock WC, Klemp JB, Dudhia J, Gill DO, Barker DM, Duda MG, Huang XY, Wang W, Powers JG (2008) A description of the advanced research WRF version 3. NCAR technical note, NCAR/ TN-475+STR. Mesoscale and Microscale Meteorology Division, National Center for Atmospheric Research, Boulder, pp 1-113

Srinivas CV, Bhaskar Rao DV, Yesubabu V, Baskaran R, Venkatraman B (2013) Tropical cyclone predictions over the Bay of Bengal using the high-resolution Advanced Research Weather Research and Forecasting (ARW) model. Q J R Meteorol Soc 139:18101825. doi:10.1002/qj.2064

Strachan J, Vidale PL, Hodges K, Roberts M, Demory M-E (2013) Investigating global tropical cyclone activity with a hierarchy of AGCMs: the role of model resolution. J Clim 26(1):133-152. doi:10.1175/JCLI-D-12-00012.1
Wang B, Wu R, Lau KM (2001) Inter-annual variability of the Asian summer monsoon: contrasts between the Indian and the western North Pacific-East Asian monsoons. J Clim 14:4073-4090. doi:10.1175/1520-0442(2001)014<4073:IVOTAS>2.0.CO;2

Wu R, Wang B (2001) Multi-stage onset of the summer monsoon over the western North Pacific. Clim Dyn 17:277-289. doi:10.1007/ s003820000118

Yang MJ, Braun SA, Chen DS (2011) Water budget of Typhoon Nari (2001). Mon Weather Rev 139:3809-3828. doi:10.1175/ MWR-D-10-05090.1

Zhou L, Murtugudde R (2014) Impact of northward-propagating intraseasonal variability on the onset of Indian summer monsoon. J Clim 27:126-139. doi:10.1175/JCLI-D-13-00214.1 